\title{
Use of Social Networks for Personalization of Electronic Education
}

\author{
Gulara A.Mammadova, Firudin T.Aghayev, Lala A. Zeynalova \\ Institute of Information Technology of ANAS, Baku, Azerbaijan
}

Received: 18 October 2018; Accepted: 17 December 2018; Published: 08 March 2019

\begin{abstract}
Currently, modern social technologies are used by hundreds of millions of users, are available free of charge, attractive and interesting. The article discusses the possibility of the use of social networks to improve elearning institution of higher education. Considering the large amount of information disseminated by university students on the social network, it is proposed to use methods of data clustering - k-means (k-means) in the article, to personalize the content of educational materials. The results of the research can be used by teachers and instructors of higher education institutions to improve the content of the e-course and personalize e-learning.
\end{abstract}

Index Terms: Social network, e-education, personalization of educational content, clustering methods.

(C) 2019 Published by MECS Publisher. Selection and/or peer review under responsibility of the Research Association of Modern Education and Computer Science.

\section{Introduction}

Scientific achievements in the field of information technologies at the beginning of the 21 st century led to the development of the concept of personal education (PLE - Personal Learning), the idea of which was to provide educators and curators of e-courses with the ability to customize training to the needs of each individual trainee. The concept of "Personalization of education" is broader than simply "individualization" or "differentiation", since it gives the learner a definite choice of what is being studied, when it is studied and how it is studied.

Personalized learning is the adaptation of the pedagogy, curriculum and learning environments to meet the needs and styles of the individual students learning. The key elements that are customized in personalized elearning are: the pace of learning, the learning approach, learning activities, educational content. In a truly personalized e-learning environment, students are given the opportunity to learn what they want, when they want, and even the method of teaching! [1-4]

* Corresponding author.

E-mail address: depart10@iit.ab.az 
The personalization of education is directly related to the need for a transition to a knowledge society, when the learner is at the center of the educational process and the learning is carried out at the place of his finding, and the educational environment is being built up for him.

Many foreign universities, realizing this, have started creating educational management systems (LMS) that allow personalizing educational environments [5], such as the Bolton University of Manchester in England.

In fact, we are not talking about the individualization of education, but about personal education, the formation of a personal educational space (that is, the actual creation of "cyber personality" in the educational space). This, in full measure, allows you to take into account the personal psycho-physiological characteristics of the learner: from the rate of mastering knowledge to genetic characteristics.

Currently, it is common to use the Learning Management System (LMS) throughout the world at universities. However, these platforms are used mainly for administrative purposes, and its educational effect is of little importance. In such systems, for the educational perspective, students have the opportunity to check the learning content, and they can interact with their classmates and teachers. However, the rigid structure of the general systems of e-learning management does not stimulate the active participation of the learner in the learning process and the improvement of his knowledge.

The understanding of this led in the first decade of the 21 st century to numerous attempts to create a learning environment in which the students learning environment was linked to the personal spaces of other learners to effectively share knowledge and create new knowledge together. The use of social applications and social networks provides a different approach to e-learning than that provided by the use of learning management systems.

The social network expands the individual needs of the student in the learning process, and also provides contact with a large number of people who share the same interests and goals. Therefore, this article explores the possibilities of using social networks to improve e-education by personalizing the content of educational materials. To identify similar content educational materials distributed by students in a social network, the method of k-means data clustering is used.

\section{Related Work}

The analysis of social networks is based on the mathematical theory of graphs. It is presented in the work of the Hungarian mathematician Erdos [6]. Mathematically, a network is a set of nodes (in our example, these are students of the universitets) connected by lines characterizing the relations between nodes. Each relation connects several nodes. The first fundamental research of social networks dates back to 1979 and is reflected in the work of Welman [7]. He developed cluster modeling algorithms and basic metrics for analyzing social networks.

The analysis of social networks is aimed at studying relations between people, considers social interaction in terms of network theory. These terms include nodes (individuals within the network) and links or links (representing relationships between individuals).

In the publications of some researchers - Bennett S., Bishop A., Dalgarno B., Purcell B.K., Xe X., Schröder A., Minokha S., Schneider S. and others discuss the possibilities of wide use of social networks in higher education. [8-11]. They even argue that social technologies support constructivist approaches to learning and have the opportunity to exchange online learning more than it did in traditional learning environments. They highlight the benefits of using social networks as tools for developing a new style of learning, and negative impacts that can affect the learning process in order to provide a justification for using social networks in higher education. In their works, they show that social networks have become a ubiquitous tool for communication, entertainment and non-formal education for both students and teachers.

Social technologies support flexibility in learning processes and ensure easy publication, exchange of ideas and re-use of study content and comments. They also support links to relevant resources in the information environment run by students and lecturers themselves. In addition, some authors argue that educational activities in social networks are valuable for the development of students' collaborative work skills, where 
students use attractive social technologies, and in some cases the use of social networks has contributed to higher indicators in learning activity [12].

In addition, thanks to the use of social technologies such as blogs, wikis and social networking sites, students are more likely to become more active. It allows students to express themselves more freely, as they are given the freedom to publish their work on the Internet through blogs and wikis. Using social technologies can further increase the motivation of students and draw attention to detail, which will lead to a general improvement in the quality of work. The authors noted that when students publish their work in a social network, their work is mostly original, interesting and attractive to others, is positively evaluated by peers and teachers [13].

So, Terry Anderson and Jon Dron Anderson[14] in his article "Integrating learning management and social networking systems" told about the Athabasca Landing system (Athabasca University in Canada) that uses a social environment to improve teaching or learning. This system uses the Elgg (elgg.org) based social media and network platform to create a social networking application that can be used by any teacher, administrator or student at Athabasca University to create many different kinds of individual, group, network and set communications.

Another author - Veeramanickam Murugappan [15] from Department of Computer Sciences and Engineering, Karpagam University (India) in article "A Smart E-Learning System for Social Networking" describes a smart cloud e-learning system with social networking based on architecture level of social networking and $\mathrm{E}$ learning cloud system to support $\mathrm{E}$ learning interactions in worldwide environments.

Julian McAuley and Jure Leskovec from Stanford university (USA) have developed [16] a novel machine learning task of identifying users' social circles. This model is used to detect ego-nodes in a social network that combines the structure of a network, as well as user profile information. For each such node, they identified its members and a profile similarity profile for a particular circle.

Tianyi Hao and Longbo Huang (Institute for Interdisciplinary Information Sciences, Tsinghua University) in their work "A Social Interaction Activity based Time-Varying User Vectorization Method for Online Social Networks" [17] are considering the problem of user modeling in online social networks, and propose a social interaction activity based user vectorization framework, called the time- varying user vectorization (Tuv), to infer and make use of important user features. This method allowed them to extract hidden user properties in a social network and study the interaction of students and teachers.

\section{Distinctive Features of Standard Education Management Systems and Systems using Social Networks}

Although most social networks that currently exist have not been designed for educational purposes, they have certain functions that can be very interesting and important in the educational process. There are some tools for supporting e-learning, including blogs, discussion forums, chat rooms, file sharing, video conferencing, electronic portfolio and wiki. All of them can be used to support activities related to the learning process. Some of these tools can be integrated into e-learning platforms. Figure 1 shows a diagram of the joint training platform, using a social network.

For example, social networking blogs can be used by students to spread their ideas, publish their work, and bookmarks allow students to add hyperlinks to view certain sites by students with similar interests. To place multimedia information, you can use the file sharing network - YouTube.

Social technologies can be used by students to jointly study ways to solve their problems with group members or to organize joint training and learning groups. Cooperating with peers, they expand their formal and informal interactions, establish an active relationship with them, seek to work with concrete results or produce results in online and offline modes.

The use of social networks to support e-learning is part of an active and social type of education in which students are problem-oriented. The main points of the learning process are self-regulatory actions to solve problems, which involves an approach to social constructivism, in which the student must manage his own learning process. This type of training means that it is impossible to structure and determine in advance the student's actions in the learning process. Actions should start with a problem or project, and the network in turn 
provides tools and resources that support the learner in the problem-solving process. Table 1 shows the distinguishing features of e-learning platforms and the use of social networks [18].

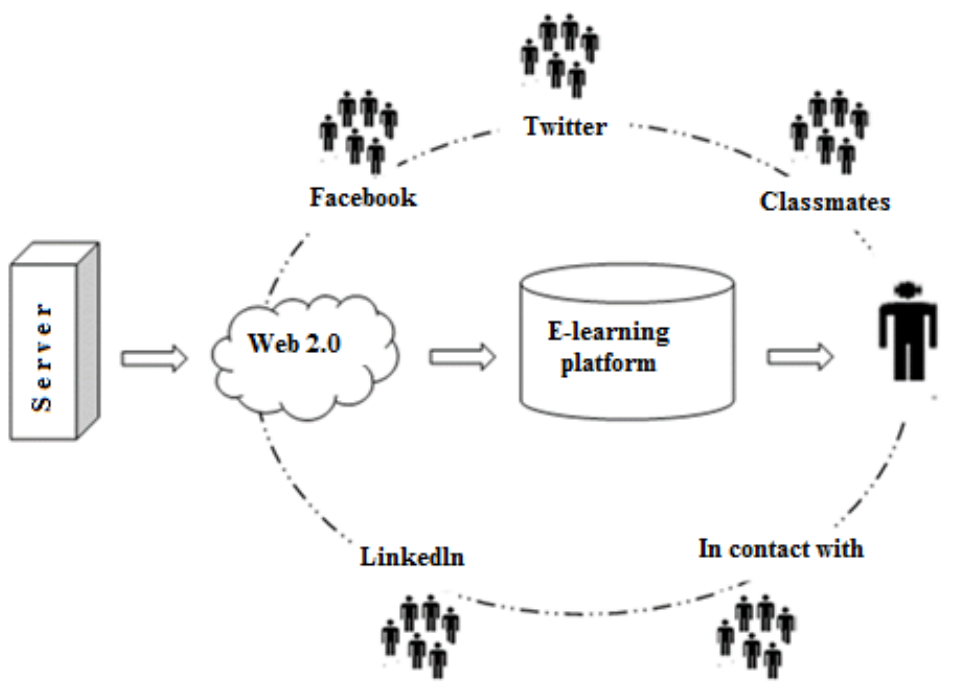

Fig.1. Collaborative E-Learning Environment with Online Social Networks

Table 1. Distinctive Features of E-Learning Platforms and Social Networks

\begin{tabular}{|l|l|}
\hline \multicolumn{1}{|c|}{ E-Learning Platform } & \multicolumn{1}{c|}{ Social Networking } \\
\hline A limited environment for platform users. & $\begin{array}{l}\text { It covers the entire network of friends and friends of his friends, } \\
\text { depending on the degree of confidentiality. }\end{array}$ \\
\hline $\begin{array}{l}\text { The student plays a passive role. He can only access the } \\
\text { material provided by the teacher. }\end{array}$ & $\begin{array}{l}\text { The student plays an active role. Takes part in the formation of } \\
\text { learning processes. }\end{array}$ \\
\hline $\begin{array}{l}\text { The content is developed by the teacher and used by the } \\
\text { learner. }\end{array}$ & $\begin{array}{l}\text { The student himself can create content and share his content with } \\
\text { others }\end{array}$ \\
\hline $\begin{array}{l}\text { Communication occurs mainly in one direction: teacher } \Rightarrow \\
\text { student. }\end{array}$ & Communication takes place in both directions. \\
\hline $\begin{array}{l}\text { The student is the recipient of knowledge. Its critical } \\
\text { meaning is not stimulated. }\end{array}$ & $\begin{array}{l}\text { The social network stimulates a critical comprehension of the } \\
\text { acquired knowledge by the student. Interaction with different people } \\
\text { and opinions encourages the student to develop his critical approach. }\end{array}$ \\
\hline
\end{tabular}

\section{Using Methods of Clustering Social Networks to Personalize Educational Content}

In order to draw certain conclusions about the influence of social networks in education, to simulate student interaction and to predict their behavior, it is necessary to analyze the information existing in them. Analysis of data from social networks consists of the following stages:

- Data collection;

- Data cleaning;

- Preliminary data processing;

- Tracking changes in user data;

- Choice of method for data analysis;

- Construction of graph structures; 
- Visualization of data.

Clearly, the amount of information circulating in the social network is huge. Therefore, it is necessary to clean up (cut off unnecessary information) and pre-process information (bringing information to a form convenient for its analysis). As a result of data purification, we single out information of interest in accordance with the goals set and its further processing.

Information that can be extracted from the social network to analyze the interactions between users (in this case, between students, teachers and students, instructors and students, etc.) can be the following:

- Username;

- $\quad$ The number of subscribers of this user (the number of users who read his messages);

- $\quad$ Number of friends of this user;

- $\quad$ The number of messages sent by this user to another user;

- $\quad$ The number of messages sent by the user;

- External links found in the messages of this user.

- $\quad$ Number of mentions of this user by another user;

- The number of mentions of some external link by the given user.

- The number of times a particular user's entry was viewed by other users;

- $\quad$ The number of likes (approvals) of a particular record of this user.

One of the directions of social networks analysis is the study of its structure, where all network participants (in this case, students, teachers and instructors) are considered as graph vertices connected by ribs to other network members. This method is used to simulate communication links between network users, analyze information flow and find communities on the network. Here the main attention is paid to such characteristics of the network nodes as centrality, relative location, intensity (edge weight) and directionality of interactions, clustering coefficient (measure of connectivity of network nodes) [19-21].

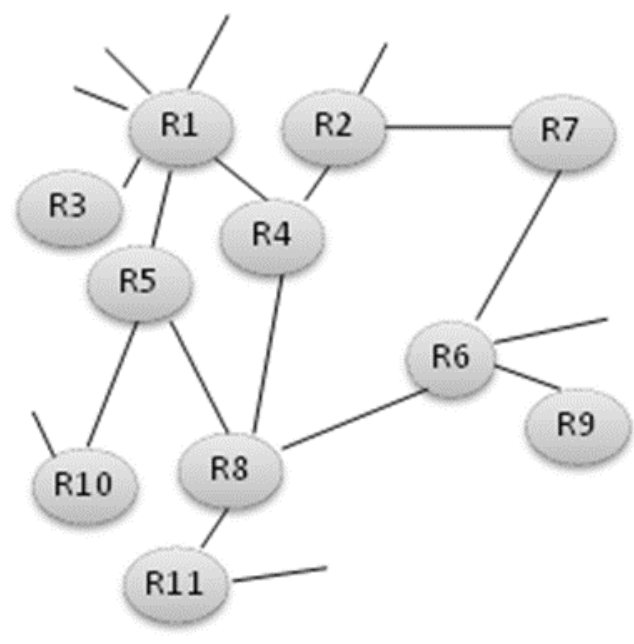

Fig.2. Fragment of Visualization of Interaction of Students in a Social Network

Visualized graphs allow us to identify the nodes that are closest, to find dense clusters of activity. One of the main parameters of the graph is "degree centrality", which expresses the ratio of the number of links of a particular node to the total number of other nodes. If for some node this parameter is 1 , this means that this node is connected to all other nodes of the network, if it is 0 , then this node is isolated. This indicator shows the 
degree of "celebrity" node, shows that the student has a great influence on the rest. Figure 2 shows a fragment of the visualized graph for analyzing student interaction in a social network. Figure 2 shows that the user of the network R1 has a higher degree of centrality than the user R3 (less communication lines are drawn from R3 than from R1).

\section{The use of K-Means for Clustering Educational Information Distributed by Students on a Social Network}

In social networks, communications can be strong or weak, depending on the intensity and frequency of communication. In order to select the necessary information from a large amount of heterogeneous data, it is necessary to use methods that allow analyzing the most important. For example, you can reduce the number of users viewed, limited to relatively popular (leaders) of them, which form the majority opinion. The leader of opinions has a large number of subscribers (friends), created messages, likes and comments from him, the information spreads faster and it affects more users.

According to some authors [22, 23], the cumulative analysis of the structure of social graphs and text data obtained from social networks is the most effective method of investigating the interactions between network users. In our article, to analyze the structure and content of information exchanged by university students in a social network, we will use data clustering methods.

For the clustering of social networking data, various methods are used: k-means and c-means, a binary cluster tree and a number of others [24, 25].

In our article, for clustering of educational information disseminated by students in the social network, we will use k-means, which is the root-mean-square deviation of the sum of the distances from each clustering object to the cluster center.

To this end, we denote by $\mathrm{N}$ the number of students registered in a particular social network who are enrolled in a related specialty at the same higher education institution course, and through $\{\mathrm{X}\}-$ the total number of training materials on the same subject matter that they exchange on the network.

Next, through $X$ we will denote the specific $i$ educational material exchanged in the network by the $N i$ number of students. Then, to compare the popularity of $X i$ educational material, we introduce the following coefficient:

$$
\kappa_{i}=\frac{N_{i}}{N}
$$

The closer this ratio is to 1 , the specific training material will be considered popular among students, closer to 0 - unpopular.

But very often we do not know the content of the educational material in advance and unite the texts that are not very similar in content to one group. For comparison of texts, such characteristics as frequency and number of used keywords in the text are widely used.

Denote by $\lambda_{\kappa}^{i}$ - the frequency of using the $k$-th keyword in some $i$-th educational material, and through $\overline{\lambda_{k}}$ the average frequency of the $k$-th keyword in all $n$ documents.

The average value of the metric of some $k$-th keyword in all $n$ documents:

$$
\overline{\lambda_{k}}=\frac{1}{n} \sum_{i=1}^{n} \lambda_{k}^{i}
$$

When comparing 2 texts of the same length, the frequency of using a certain keyword, should not be much different. 
The root-mean-square deviation of the $k$-th keyword is found as:

$$
\sigma_{k}=\frac{1}{n} \sum_{i=1}^{n}\left(\lambda_{k}^{i}-\overline{\lambda_{k}}\right)^{2}
$$

We will include teaching materials in one group, in which the root-mean-square deviation of the frequencies of occurrence of $k$ keywords is in a certain admissible range, that is, the density of the cluster core is below a certain value.

The cluster nucleus, in a general sense, is the part of the cluster elements closest to the center. It is assumed that most of the cluster data is concentrated in this area.

The radius of the cluster nucleus from the Chebyshevs' inequality [26, 27] is defined as:

$$
R_{i}=\bar{r}_{i}+\sqrt{2} * \sigma_{i}
$$

Here $\bar{r}_{i}$ is the average distance between the cluster center and the cluster elements, and $\sigma_{i}$-is the rootmean-square deviation. At least $50 \%$ of the frequencies of the keywords of the teaching materials are removed by no more than $\sqrt{2}$ standard deviations from their average value.

The cluster density is calculated as follows:

$$
\rho_{i}=\frac{R_{i}}{\overline{M_{i}}}
$$

$R_{i}$ is the radius of the cluster core, $\overline{M_{i}}$ is the number of elements that make up the nucleus. The coefficient of clustering of training materials will be the average density:

$$
\bar{\rho}=\frac{\rho_{1}+\ldots+\rho_{m}}{m}
$$

The clustering coefficient is a measure of how well the nodes of a graph are associated with a particular node. When the clustering factor is closer to the specified value - it means that the graph is tightly grouped around some nodes; when it is much smaller than the set value - this means that the links in the graph are relatively evenly distributed among other nodes. In the clusters found, the nodes of the graph are concentrated, which reflect tight connections between students of the social network exchanging the same content in the same content.

As a result of the study, it is possible to identify which educational materials are of interest to students, and which are not of particular value to them. Information obtained from social networks can be used by teachers of higher educational institutions to improve the content of educational materials and their adaptation to the individual characteristics of students.

\section{Conclusion}

In this sense, a person's hobbies, presented as a graph of teaching materials exchanged by students in some social network, provide the means for further personalization of educational content. Based on the analysis of 
the information received from the network, teachers and instructors of the higher educational institution have ideas about the interests and preferences of both individual students and groups of trainees. This information gives teachers the opportunity to improve the content of the e-course and tailor it to the individual needs of the learner.

\section{References}

[1] Starodubtsev VA, Personalization of the virtual educational environment, Pedagogical Education in Russia. 2015. № 7, p. 24-29.

[2] M. Johnson. "Personalised Learning". New Economy. vol II, no 4, 2004. pp. 224-228.

[3] Sandler, S. People v. 'personalization': Retaining the human element in the high-tech era of education. Education Week, 2012, 31(22), pp.20-22.

[4] Baker, R .S. J. D., \& Yacef, K. The state of educational data mining in 2009: A review and future visions. Journal of Educational Data Mining. 2009, 1(1), 3-17.

[5] M. Harmelen, Personal Learning Environments, Proceedings of the Sixth IEEE International Conference on Advanced Learning Technologies, USA, pp.815-816.

[6] Erdos P., Renyi A. On the evolution of random graphs // Publication of Mathematics Institute Hungary Academy of the Science. - 1960. V. 5. - P. 17-61.

[7] Wellman, B. The community question. American Journal of Sociology, 1979, 84, p. 1201-1207.

[8] Bennett S., Bishop A., Dalgarno B., Waycott J., Kennedy G., Implementing Web 2.0 technologies in higher education: A collective case study, Computers \& Education, 2012, pp. 724-729.

[9] Pursel B. K., Xie H., Patterns and Pedagogy: Exploring Student Blog Use in Higher Education, Contemporary Educational Technology, 2014, 5(2), pp.96-109.

[10] Schroeder A., Minocha S., Schneider C., The strengths, weaknesses, opportunities and threats of using social software in higher and further education teaching and learning, Journal of Computer Assisted Learning, 2010, pp.159-174.

[11] Hosny M. I., Fatima Sh., Facebok in Education: Students, Teachers, and Library Perspectives, journal of Computing, volume 4, № 6, 2012, pp.78-86.

[12] McLoughlin C. E., Lee M., Personalised and self regulated learning in the Web 2.0: International exemplars of innovative pedagogy using social software, Australasian Journal of Educational Technology 26(1), March 2010, pp. 28-43.

[13] Allen M., An Education in Facebook, Digital Culture and Education, 4 (3), 2012, pp. 213-225.

[14] Terry Anderson* and Jon Dron Anderson, T., \& Dron, J. (2017). Integrating learning management and social networking systems. Italian Journal of Educational Technology, 25(3), 5-19.

[15] Veeramanickam Murugappan. A Smart E-Learning System for Social Networking, International Journal of Electrical and Computer Engineering (IJECE) Vol. 4, No. 3, June 2014, pp. 447-455.

[16] https://cs.stanford.edu/people/jure/pubs/circles-nips12.pdf

[17] Tianyi Hao, Longbo Huang. A Social Interaction Activity based Time-Varying User Vectorization Method for Online Social Networks Proceedings. 28 International Joint Conference on Artificial Intelligence (IJCAI-18), 2018, pp. 3790-3796.

[18] Ribeiro F.M.S., Contributions of Online Social Networks for E-Learning (Dissertation), Department of Informatics University of Beira Interior, Portugal, 2010, p. 70 (On-line) https://ubibliorum.ubi.pt/bitstream/10400.6/3715/1/Contributions of Online Social Networks for ELearning.pdf

[19] V.I. Nosov, Elements of graph theory, Novosibirsk: SSUTI, 2008, p. 107.

[20] Brandes, U., and Erlebach, T. Network analysis: methodological foundations. In Springer, Lecture notes in computer science, Springer, 2005. pp 471.

[21] Charu C. Aggarwal Social Network Data Analytics. Boston: Kluwer Academic Publisher, 2011. 520 p. 
[22] Liben-Nowell, D., and Kleinberg, J. M. The link-prediction problem for social networks. In JASIST, 2007. 58(7): pp. 1019-1031.

[23] Batura T.V. Methods of analysis of computer social networks // Bulletin of Novosibirsk State University. Series: Information technology. 2012. Vol. 10, no. 4. pp. 13-28.

[24] Russell, M. A., Mining the Social Web, O’Reilly Media, 2011, p. 411.

[25] Bonatoa, A. \& Hadib, N. \& Hornc, P. \& Prałatd, P. \& Wange, C., Models of Online Social Networks. Internet Mathematics, 6(3), 2009, pp. 285-313.

[26] Medvedev, GA Theory of Probability and Mathematical Statistics for Economists; textbook and workshop for undergraduate and graduate students, Moscow: Publishing House Yurapt, 2016. - p. 284.

[27] Mishra, N. \& Schreiber, R. \& Stanton I. \& Tarjan, R. E., Finding Strongly-Knit Clusters in Social Networks. Internet Mathematics, 5(1-2), 2008, pp.155-174.

\section{Authors' Profiles}

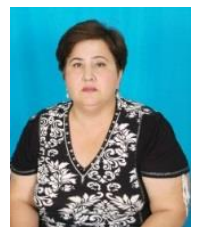

Mammadova A. Gulara graduated from mechanical-mathematical faculty of Azerbaijan State University. She is involved in a pedagogical activity at the Training Innovation Center of the Institute of Information Technology. She is dealing with formation of information culture in the educational environment, development of technological bases of electronic teaching resources, increasing teachers' ICT training issues in the direction of problems of informatization of educational process. She is the author of 20 scientific works and one thesis. She works as senior research fellow at the Institute of Information Technology.

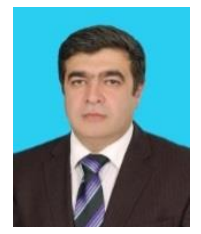

Firudin T. Aghayev graduated from "Automation and computing devices" faculty of Azerbaijan Polytechnic University. In 1997, he defended a thesis on specialty of "Distance aerospace researches" on subject of "Establishment of high speed radon-type changes in modeling process of pattern restoration methods in accordance with projections". In 2016, he was awarded with the title of associate professor by the Higher Attestation Commission under the President of the Republic of Azerbaijan.

$\mathrm{He}$ is the author of 41 articles and 3 books. Currently he is the curator at Training Innovtaion Center of Institute of Information Technology. He is the head of department of Institute of Information Technology of ANAS

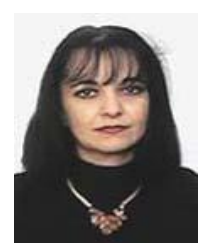

Lala A. Zeynalova graduated from the Faculty of Automatics and Computer Science, Azerbaijan Polytechnic Institute named after Ch.Ildirim. From 1986 until the appointment she worked for the ACS Department of Azerbaijan Academy of Sciences. She is engaged in training activities in the Training Innovation Center of the Institute. Research interests: data mining; social network analysis. She works as senior research fellow at the Institute.

How to cite this paper: Gulara A.Mammadova, Firudin T.Aghayev, Lala A. Zeynalova,"Use of Social Networks for Personalization of Electronic Education", International Journal of Education and Management Engineering(IJEME), Vol.9, No.2, pp.25-33, 2019.DOI: 10.5815/ijeme.2019.02.03 